\title{
Article/Artigo
}

\section{Evaluation of the six-minute walk test in patients with chronic heart failure associated with Chagas' disease and systemic arterial hypertension}

\author{
Avaliação do teste de caminhada de seis minutos em pacientes com insuficiência cardíaca \\ crônica associada à doença de Chagas e hipertensão arterial sistêmica
}

Kelly Cristina Colaço Dourado ${ }^{1}$, Reinaldo Bulgarelli Bestetti ${ }^{1}$, Augusto Cardinalli-Neto ${ }^{1}$ and José Antônio Cordeiro ${ }^{2}$

\begin{abstract}
Introduction: To evaluate physical capacity as determined by the six-minute walk test (6MWT) in patients with chronic heart failure due to Chagas' disease associated with systemic arterial hypertension (Chagas-SAH). Methods: A total of 98 patients routinely followed at the Cardiomyopathy Outpatient Service were recruited. Of these, 60 (61\%) were diagnosed with Chagas disease and 38 (39\%) with Chagas-SAH. Results: The distance walked during 6 min was $357.9 \pm 98 \mathrm{~m}$ for Chagas-SAH patients and $395.8 \pm 121 \mathrm{~m}$ for Chagas cardiomyopathy patients $(\mathrm{p}>0.05)$. In patients with Chagas-SAH, a negative correlation occurred between the 6MWT and the total score of the Minnesota Living with Heart Failure Questionnaire $(\mathrm{r}=-0.51 ; \mathrm{p}=0.001)$. No other correlations were determined between $6 \mathrm{MWT}$ values and continuous variables in patients with Chagas-SAH. Conclusions: The results of the 6MWT in Chagas-SAH patients are similar to those verified in Chagas cardiomyopathy patients with chronic heart failure. Coexistence of SAH does not seem to affect the functional capacity of Chagas cardiomyopathy patients with chronic heart failure.
\end{abstract}

Key-words: Heart failure. Chagas disease. American Trypanosomiasis. Six-minute walk test. Physical capacity. Functional capacity

\section{RESUMO}

Introdução: Avaliar a capacidade física medida pelo teste de caminhada de seis minutos em pacientes com insuficiência cardíaca crônica secundária à associação de cardiomiopatia chagásica com hipertensão arterial sistêmica (Chagas-HAS). Métodos: Noventa e oito pacientes rotineiramente tratados no Ambulatório de Cardiomiopatia do Hospital de Base foram utilizados no estudo. Deles, $60(61 \%)$ eram portadores de cardiomiopatia chagásica (ChCM), enquanto 38 (39\%) apresentavam a associação Chagas-HAS. Resultados: A distância média caminhada foi de $357,9 \pm 98 \mathrm{~m}$ no grupo Chagas-SAH e $395,8 \pm 121 \mathrm{~m}$ no grupo $\mathrm{ChCM}(\mathrm{p}>0,05)$. Nos pacientes com Chagas-SAH, houve correlação negativa entre o Teste de Caminhada de 6 Minutos e a somatória de pontos obtida no Questionário Vivendo com a Insuficiência Cardíaca. $(r=-0,51 ; p=0,001)$. Nenhuma outra correlação foi observada entre o teste de caminhada de seis minutos e as variáveis contínuas examinadas no grupo ChagasSAH. Conclusões: Os resultados do teste de caminhada de seis minutos em pacientes com Chagas-SAH são semelhantes aos observados em pacientes com ChCM. A coexistência de HAS parece não afetar a capacidade funcional de pacientes com a associação de cardiomiopatia da doença de Chagas e HAS.

Palavras-chaves: Insuficiência cardíaca. Doença de Chagas. Trypanossomíase Americana. Teste de caminhada de seis minutos. Capacidade física. Capacidade funcional.

1. Department of Cardiology and Cardiovascular Surgery, Hospital de Base, School of Medicine of São José do Rio Preto, SP, Brazil. 2. Department of Statistics, Hospital de Base, School of Medicine of São José do Rio Preto, SP, Brazil.

Address to: Dr. Reinaldo Bulgarelli Bestetti. Hospital de Base/Setor de Eletrocardiografia/FAMERP. Av. Brigadeiro Faria Lima 5544, 15090-000 São José do Rio Preto, SP, Brazil.

Phone: 55 17 3201-5065

e-mail: rbestetti@netsite.com.br

Received in 04/04/2010

Accepted in 07/05/2010

\section{INTRODUCTION}

Approximately 11 million people are affected by Chagas' disease in Latin America. The disease is caused by the protozoan Trypanosoma cruzi, which is transmitted to humans through contact with the feces of a biting bug ${ }^{1}$. Chagas' disease can now be found throughout the world due to international immigration ${ }^{2}$.

Initial infection occurs in early childhood in the majority of cases and about $30 \%$ of patients will develop Chagas' cardiomyopathy up to 20 years later ${ }^{3}$. Chagas' cardiomyopathy is clinically characterized by the appearance of atrioventricular blocks ${ }^{4}$, dysrhythmias ${ }^{5}$, thromboembolism ${ }^{6,7}$, chest pain ${ }^{8}$, sudden cardiac death ${ }^{9}$ and chronic heart failure ${ }^{10}$.

Systemic arterial hypertension can affect about $30 \%$ of inhabitants in areas where Chagas' disease is endemic ${ }^{11}$ and it may also compromise about $33 \%$ of Chagas' disease patients ${ }^{12}$. Chronic heart failure can affect $8 \%$ of patients with both conditions ${ }^{12}$.

In patients with chronic heart failure associated with Chagas' disease-systemic arterial hypertension (Chagas-SAH), no data exist regarding functional capacity. In fact, Chagas cardiomyopathy is characterized by the presence of mononuclear cell infiltrate along with reparative fibrosis throughout the myocardium ${ }^{13}$, accompanied by myocytolysis and vasospasm of the microvasculature in a similar fashion to that observed in catecholamine cardiomyopathy ${ }^{14}$.

Therefore, the additional burden posed by systemic arterial hypertension could aggravate the appearance of myocardial fibrosis, microvasculature spasm and autonomic imbalance of Chagas' disease patients ${ }^{15}$, ultimately affecting the functional capacity of patients with this condition.

Therefore, the purpose of this study was to evaluate functional capacity in patients with chronic heart failure due to Chagas-SAH using the 6-minute walk test. 


\section{METHODS}

\section{Patients}

A total of 98 patients routinely followed up at the Cardiomyopathy Outpatient Service of Hospital de Base from January from 2004 to January 2008 were recruited for the study. Of these, 60 (61\%) were diagnosed with Chagas cardiomyopathy and 38 (39\%) with Chagas-SAH. The diagnosis of Chagas' disease was based on positive serology and the diagnosis of SAH when systolic arterial pressure was $>140 \mathrm{mmHg}$ and/or diastolic blood pressure was $>90 \mathrm{mmHg}$. Patients with normal pressure values, but with previous history of $\mathrm{SAH}$ who were taking antihypertensive medicine on admission were also considered to have SAH.

To be included in the study, patients had to present; 1) left ventricular ejection fraction $<55 \%$ on their echocardiograph, 2 ) the absence of any other disease that could induce heart disease by itself. Patients with physical incapacity that precluded clear communication with the researcher to the point of interfering in the 6-minute walk test (6MWT) performance were also excluded from the investigation.

All patients underwent clinical history, physical examination, standard laboratory tests, 12-lead ECG, chest X-Ray, and 2D Dopplerechocardiography. Patients with New York Heart Association class I/II symptoms were treated with B-blockers (carvedilol, targeted dose $50 \mathrm{mg} /$ day, or metoprolol succinate, targeted-dose $200 \mathrm{mg} /$ day) and angiotensin converting enzyme inhibitors (ACEI), [enalapril (targeted dose $20 \mathrm{mg} /$ day), or captopril (targeted-dose $75 \mathrm{mg} /$ day) ], or losartan (targeted dose $50 \mathrm{mg} /$ day). Patients with New York Heart Association Class III/IV were treated with digoxin and furosemide to alleviate symptoms, as well as ACEI/losartan at targeted doses and spironolactone ( 25 to $50 \mathrm{mg} /$ day). The daily dose of each drug was that taken at the time of the 6MWT performance. All patients also replied to the Minnesota Living with Heart Failure Questionnaire (MLWHFQ) ${ }^{16}$, as previously described ${ }^{17}$.

\section{The 6-minute walk test}

After written, free, informed consent was obtained from each patient, for whom information regarding the objectives, methods and potential risks was provided, the $6 \mathrm{MWT}$ was performed.

The 6-minute walk test was performed in a hallway surface, $30 \mathrm{~m}$ in length, located in the Outpatient Service of the Hospital de Base. All the patients were supervised by a physiotherapist (KCCD) during the testing. Patients were allowed to stop walking if they developed either shortness of breath or fatigue; however, they were permitted to walk after the symptoms ceased if still within $6 \mathrm{~min}$ of initiating testing. Heart rate was measured before walking, 3 and 6 minutes after initiating walking. Blood pressure was measured before and $3 \mathrm{~min}$ after the test ended with a manual sphygmomanometer in the antecubital vein, with patients seated for $15 \mathrm{~min}$ in a comfortable chair. None of the patients presented complications related to the 6MWT.

\section{Statistical analysis}

Unless indicated otherwise, data are expressed as mean \pm standard deviation. Continuous variables between two groups were compared by the $\mathrm{T}$ Test for unpaired data, whilst categorical variables between two groups were compared by the Fischer exact test. Correlation between continuous variables in each group was established by the Spearman test, in which an $r$ value $>0.50$ was considered significant. In all circumstances, differences at the level of $\mathrm{p}<0.05$ were considered statistically significant.

\section{Ethical}

The study was approved by the local ethics in research committee (Resolution 077/2006).

\section{RESULTS}

Patient demographics are presented in Table $\mathbf{1 .}$

Mean sodium serum levels were $140.8 \pm 4.0 \mathrm{mEq} / \mathrm{L}$ in Chagas' disease patients and $141.3 \pm 5.0 \mathrm{mEq} / \mathrm{L}$ in Chagas-SAH $(p>0.05)$, whereas mean potassium serum levels were $4.4 \pm 0.3 \mathrm{mEq} / \mathrm{L}$ in Chagas' disease patients and $4.3 \pm 0.6 \mathrm{mEq} / \mathrm{L}$ in Chagas-SAH. Mean creatinine serum levels were $1.2 \pm 0.3 \mathrm{mg} / \mathrm{dL}$ in Chagas' disease patients and $1.3 \pm 0.4$ in Chagas-SAH $(p>0.05)$, and the hemoglobin levels were $13.3 \pm 1.4 \mathrm{~g} / \mathrm{L}$ in Chagas' disease patients and $12.9 \pm 1.5$ in Chagas-SAH $(\mathrm{p}>0.05)$.

TABLE 1 - Demographics among Chagas disease $(n=60)$ and Chagas-SAH $(\mathbf{n}=38)$ patients.

\begin{tabular}{lccc}
\hline & Chagas-SAH & Chagas disease & P value \\
\hline Age (years) & $63 \pm 10$ & $55 \pm 14$ & $\mathrm{~ns}$ \\
Male & $26(88 \%)$ & $41(68 \%)$ & $\mathrm{ns}$ \\
NYHA Class III/IV & $8(21 \%)$ & $15(25 \%)$ & $\mathrm{ns}$ \\
Heart Rate (bpm) & $73 \pm 9$ & $74 \pm 8$ & $\mathrm{~ns}$ \\
SAP (mmHg) & $128 \pm 15.3$ & 112.213 .6 & 0.02 \\
ACEI/ARB & $14(37 \%)$ & $49(82 \%)$ & $<0.0005$ \\
Beta-Blockers & $11(29 \%)$ & $15(25 \%)$ & $\mathrm{ns}$ \\
Diuretics & $14(37 \%)$ & $49(82 \%)$ & $<0.0005$ \\
Amiodarone & $9(24 \%)$ & $39(65 \%)$ & $<0.0005$ \\
LWHF score & $41.3 \pm 20.6$ & $37.7 \pm 21.4$ & $\mathrm{~ns}$ \\
\hline
\end{tabular}

NYHA: New York heart Association Class; bpm=beats per minute; SAP: systolic anterior pressure, converting enzyme inhibitor/angiotensin receptor of bradykinin.

Cardiomegaly verified in the chest X-ray was observed in $16(27 \%)$ of Chagas' disease patients and in 16 (43\%) Chagas-SAH patients $(\mathrm{p}=0.003)$. Pulmonary venous congestion was detected in none of the Chagas' disease patients, but in 5 (13\%) Chagas-SAH patients $(\mathrm{p}=0.007)$.

Table 2 depicts electrocardiographic variables observed in Chagas' disease and in Chagas-SAH. The echocardiographic variables obtained in this study are presented in Table 3.

TABLE 2 - Comparison of electrocardiographic findings in Chagas $(n=60)$ and Chagas-SAH $(n=38)$ cardiomyopathy groups.

\begin{tabular}{lccc}
\hline & $\begin{array}{c}\text { Chagas-SAH } \\
\mathrm{n}(\%)\end{array}$ & $\begin{array}{c}\text { Chagas disease } \\
\mathrm{n}(\%)\end{array}$ & P value \\
\hline Non-sinus rhythm & $10(26.0)$ & $31(52.0)$ & 0.02 \\
Pacemaker & $9(24.0)$ & $19(32.0)$ & $\mathrm{ns}$ \\
Atrial fibrillation & $1(3.0)$ & $12(20.0)$ & 0,01 \\
RBBB & $1(3.0)$ & $24(40.0)$ & $<0.0005$ \\
LBBB & $4(10.0)$ & $3(5.0)$ & $\mathrm{ns}$ \\
LAFB & $3(8.0)$ & $3(7.0)$ & $\mathrm{ns}$ \\
PVC & $13(34.0)$ & $19(32.0)$ & $\mathrm{ns}$ \\
LVH & $16(42.0)$ & $5(8.0)$ & 0.007 \\
Necrosis & $3(8.0)$ & $8(13.0)$ & $\mathrm{ns}$ \\
Ischemia & $4(10.0)$ & $6(10.0)$ & $\mathrm{ns}$ \\
Low Voltage QRS & $6(16.0)$ & $23(38.0)$ & 0.01 \\
\hline
\end{tabular}

RBBB: right bundle branch block, LBBB: left bundle branch block, LAFB: left anterior fascicular block, PVC: premature ventricular contractions, LVH: left ventricular hypertrophy. 
TABLE 3 - Comparison of echocardiographic variables in Chagas $(n=60)$ and Chagas-SAH ( $\mathbf{n = 3 8})$ groups.

\begin{tabular}{lccc}
\hline & Chagas-SAH & Chagas disease & p value \\
\hline LVEF $(\%)$ & $51.8 \pm 12.9$ & $44.9 \pm 13.8$ & 0.001 \\
LAD (mm) & $43.9 \pm 7.7$ & $46.5 \pm 8.5$ & 0.01 \\
LVDD (mm) & $52.7 \pm 10.9$ & $61.6 \pm 9$ & $<0.0005$ \\
LV Mass $(\mathrm{g})$ & $261 \pm 72$ & $317.6 \pm 77.5$ & $<0.0005$ \\
LVAA & $3(8 \%)$ & $8(13 \%)$ & $\mathrm{ns}$ \\
MR & $10(23 \%)$ & $53(88 \%)$ & $<0.0005$ \\
Akinesia & $0(0 \%)$ & $12(20 \%)$ & 0.03 \\
Hypokinesia & $9(24 \%)$ & $27(45 \%)$ & 0.03 \\
\hline
\end{tabular}

LVEF: left ventricular ejection fraction, LAD: left atrium dimension, LVDD: left ventricular diastolic dimension, $\mathbf{L V}$ : left ventricle, $\mathbf{M R}$ : mitral regurgitation.

The mean distance walked during $6 \mathrm{~min}$ was $357.9 \pm 98 \mathrm{~m}$ for Chagas-SAH patients and $395 \pm 121 \mathrm{~m}$ for Chagas disease patients $(\mathrm{p}>0.05)$. Figure 1 illustrates the results of the 6MWT. The proportion of patients who walked less than $300 \mathrm{~m}$ was 11 out of 38 (29\%) individuals among Chagas-SAH patients and 9 out 60 (15\%) individuals among Chagas' disease patients $(\mathrm{p}>0.05)$.

In patients with Chagas-SAH, a negative correlation was determined between the 6MWT and the total score of the MLWHFQ $(\mathrm{r}=-0.51 ; \mathrm{p}=0.001)$, as illustrated in Figure 2. No other correlations were determined between the $6 \mathrm{MWT}$ and continuous variables in patients with Chagas-SAH. A tendency toward a correlation was determined between the 6MWT and hemoglobin levels $(\mathrm{r}=0.34$; $\mathrm{p}=0.007)$ and the total score of the MLWHFQ $(\mathrm{r}=-0.38 ; \mathrm{p}=0.003)$ in the Chagas disease group.

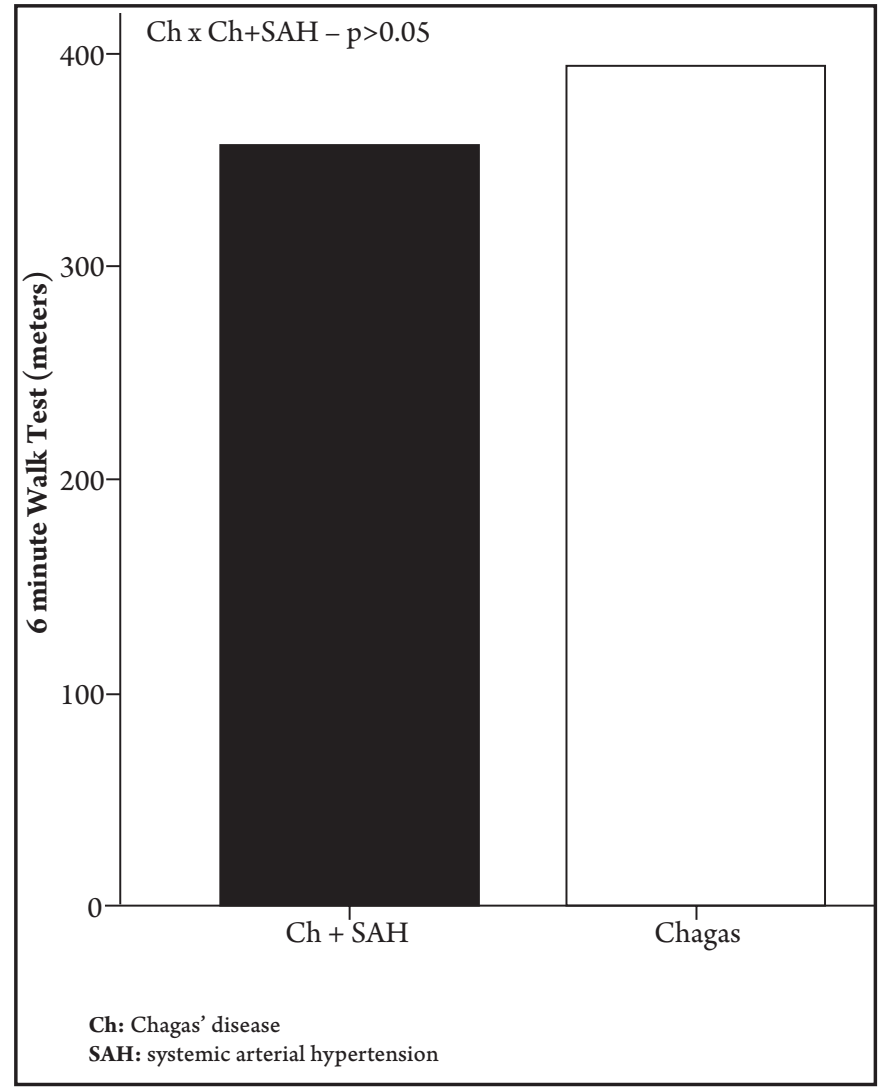

FIGURE 1 - Results of the 6-minute walk test according to the groups studied.

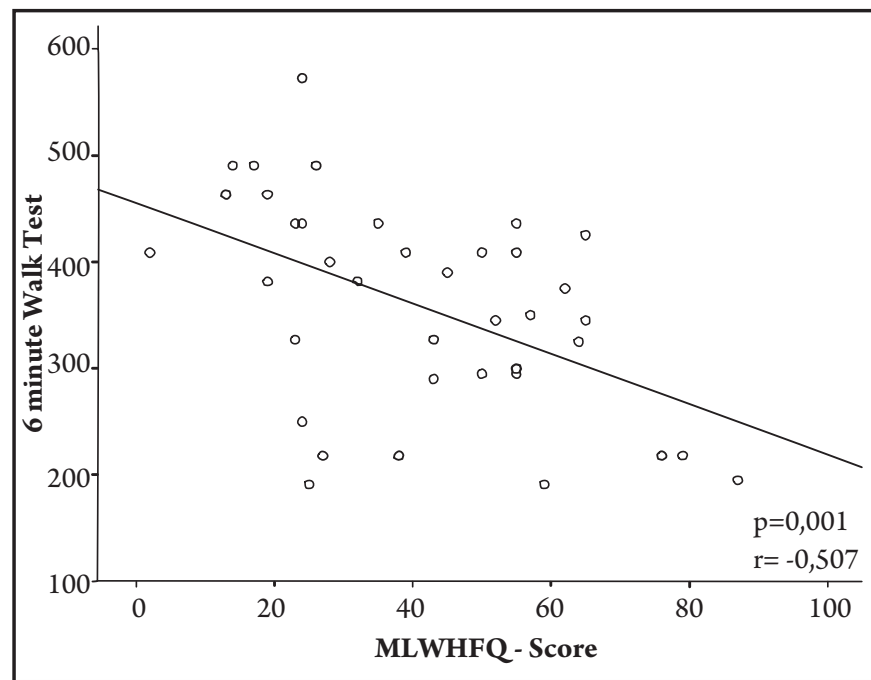

FIGURE 2 - Correlation between the 6-minute walk test and the Minnesota living with heart failure questionnaire in patients with Chagas-SAH patients with chronic heart failure.

\section{DISCUSSION}

This study shows that patients with Chagas-SAH walked a similar distance to Chagas' disease patients during the 6-minute walk test. Thus, in contrast to what might have been expected, the presence of SAH does not seem to adversely impact on physical capacity in Chagas' disease patients with chronic heart failure.

A negative correlation was determined between the score of the Minnesota Living with Heart Failure Questionnaire (MLWHFQ) and the $6 \mathrm{MWT}$ in patients with Chagas-SAH in this study. The questionnaire measures the self-perception of well-being in physical and emotional dimensions in patients with chronic heart failure. The physical dimension is closely related to physical capacity, so that the higher the score of well being, the lower the physical status ${ }^{16}$. Not surprisingly, therefore, in patients with Chagas-SAH, a similar negative correlation was determined between well-being selfperception and physical capacity, as detected by the 6MWT.

No difference was verified in the distance walked by Chagas' disease and Chagas-SAH patients with chronic heart failure. Nonetheless, it is necessary to bear in mind that the distance walked by Chagas' disease patients in this study was shorter than that walked in the study by Souza et $\mathrm{al}^{18}$. In this regard, it is important to note that the left ventricular ejection fraction, which correlates well with the 6MWT results, was similar in both studies. In the study by Souza et $\mathrm{al}^{18}$, however, patients were not permitted to take B-blockers. In contrast, B-blockers were an integral component of the treatment of Chagas' disease patients in the present study. Therefore, this disparity in treatment approach may account for the difference in the distance walked in the 6MWT in both studies.

Another interesting finding of this investigation was the similarity in the resting heart rate in Chagas-SAH and Chagas' disease patients. In the context of chronic heart failure, the resting heart rate has long been recognized as a reflex of peripheral sympathetic activity. In patients with Chagas disease-SAH with no chronic heart failure, parasympathetic impairment has been observed in basal conditions and in response to orthostatic stress ${ }^{19}$. In patients with chronic heart failure secondary to Chagas-SAH, however, such autonomic 
derangement does not seem to affect the resting heart rate more than in Chagas cardiomyopathy patients.

Another point that deserves further consideration is related to the clinical aspects of patients with Chagas-SAH chronic heart failure. Gurgel and Almeida ${ }^{20}$ performed a clinical-pathological correlation in 103 autopsied patients with chronic Chagas' heart disease, 33\% of them presenting SAH. The authors observed no difference in Chagas' disease patients with or without $\mathrm{SAH}$ regarding the proportion of right bundle branch block or left anterior fascicular block on the 12-lead electrocardiogram. Bertanha et $\mathrm{a}^{21}$ studied 125 patients with Chagas' disease with no manifest chronic heart failure, $55 \%$ with $\mathrm{SAH}$. The authors observed no difference regarding the proportion of electrocardiographic abnormalities in patients with and without SAH. In this study, however, Chagas' disease patients showed a higher proportion of right bundle branch block than Chagas-SAH patients. This discrepancy between these studies may be accounted for by the fact that in the study by Gurgel and Almeida ${ }^{20}$, only $6 \%$ of patients had chronic heart failure and none had chronic heart failure in the study by Bertanha et $\mathrm{al}^{21}$, thus suggesting that intraventricular conduction delay is more prevalent in the presence of overt chronic heart failure.

Patients with Chagas-SAH used amiodarone less frequently than patients with Chagas' disease heart failure. Since amiodarone use increases the physical dimension score of the MLWHFQ, denoting decreased functional capacity in Chagas' disease patients ${ }^{17}$, it might be expected to see an adverse effect of this drug on the 6MWT of Chagas-SAH patients; however, this was not the case. Such a finding, therefore, suggests that drugs which provoke changes in the selfperception of the patient's well-being do not necessarily have an adverse effect on the $6 \mathrm{MWT}$ as well.

The proportion of patients who walked a distance of less than 300 meters was similar in Chagas' disease and Chagas-SAH patients. This is an important point, since non-Chagas' disease patients with similar physical incapacity have a poor 6-month prognosis ${ }^{22}$. Although this study was not powered to evaluate mortality, the results of this investigation also suggest that the presence of SAH does not impact on markers of mortality, at least not those detected by the 6-minute walk test.

In conclusion, the results of the 6-minute walk test in Chagas$\mathrm{SAH}$ patients are similar to those verified in Chagas' disease with chronic heart failure. A negative correlation was determined between the 6-minute walk test and the total score of the Minnesota Living with Heart Failure Questionnaire. The coexistence of systemic arterial hypertension does not seem to affect the functional capacity of Chagas' disease patients with chronic heart failure.

\section{CONFLICT OF INTEREST}

The authors declare that there is no conflict of interest.

\section{REFERENCES}

1. Anonymous. A human rights-based approach to neglected tropical diseases. http://apps.who.int/tdr/svc/publication/tdr.researchpublications/humanrights. Accessed on August 20; 2009.

2. Schmunis GA. Epidemiology of Chagas disease in non-endemic countries: the role of international migration. Mem Inst Oswaldo Cruz 2007; 102(suppl):75-85.

3. Laranja FS, Dias E, Miranda A, Nóbrega G. Chagas' disease. A clinical, epidemiologic, and pathologic study. Circulation 1956; 14:35-60.
4. Rassi-Jr A, Rassi AG, Rassi SG, Rassi-Jr L, Rassi A. Ventricular arrhythmias in Chagas' disease. Diagnostic, prognostic, and therapeutic peculiarities. Arq Bras Cardiol 1995; 65:377-387.

5. Bestetti RB, Santos CRF, Machado-Jr OB, Ariolli MT, Carmo JL, Costa NK, et al. Clinical profile of patients with Chagas' disease before and during ventricular tachycardia. Int J Cardiol 1990; 29:39-46.

6. Bestetti RB. Stroke in a hospital-derived cohort of patients with chronic Chagas disease. Acta Cardiol 2000; 55:33-38.

7. Carod-Artal FJ, Vargas AP, Horan TA, Nunes LG. Chagasic cardiomyopathy is independently associated with ischemic stroke in Chagas' disease. Stroke 2005; 36:965-970.

8. Bestetti RB, Ariolli MT, Carmo JL, Santos CRF, Machado-Jr O, Costa NK, et al. Clinical characteristics of acute myocardial infarction in patients with Chagas' Disease. Int J Cardiol 1992; 35:371-376.

9. Bestetti RB, Cardinalli-Neto A. Sudden cardiac death in Chagas' disease in the contemporary era. Int J Cardiol 2008; 131:9-17.

10. Bestetti RB, Theodoropoulos TAD, Cardinalli-Neto A, Cury PM. Treatment of chronic systolic heart failure secondary to Chagas heart disease in the current era of heart failure therapy. Am Heart J 2008; 156:422-430.

11. Freitas OC, Carvalho FR, Neves JM, Veludo PK, Parreira RS, Gonçalves RM, et al. Prevalence of systemic arterial hypertension in the urban population of Catanduva city, São Paulo state, Brazil. Arq Bras Cardiol 2001; 77:9-15.

12. Gurgel CBFM, Miguel-Jr A, Mendes CR, Zerbini CO, Carcioni TM. Frequency of arterial hypertension in chronic Chagas' disease. A retrospective study. Arq Bras Cardiol 2003; 81:541-544.

13. Rossi MA, Ramos SG, Bestetti RB. Chagas' heart disease: clinical-pathological correlation. Front Biosci 2003; 8:e94-109.

14. Bestetti RB, Ramos CP, Figueredo-Silva J, Sales-Neto VN, Oliveira JSM. Ability of the electrocardiogram to detect myocardial lesions in isoproterenol-induced rat cardiomyopathy. Cardiovasc Res 1987; 21:916-921.

15. Bestetti RB. Role of parasites in the pathogenesis of Chagas' cardiomyopathy. Lancet 1996; 347:913-914.

16. Rector T, Cohn J. Assessment of patient outcome with the Minnesota Living With Heart Failure Questionnaire: reliability and validity during a randomized, double-blind, placebo-controlled clinical trial of pimobendan. Am Heart J 1992; 124:1017-1025.

17. Dourado KCC, Bestetti RB, Cordeiro JA, Theodoropoulos TAD. Assessment of quality of life in patients with chronic heart failure secondary to Chagas' cardiomyopathy. Int J Cardiol 2006; 108:412-413.

18. Souza L, Botoni FA, Britto RR, Rocha MOC, Teixeira-Jr AL, Teixeira MM, et al. Six-minute walk test in Chagas' cardiomyopathy. Int J Cardiol 2008; 125:139-141.

19. Miziara AN, Molina RJ, Ferreira BDC, Barbosa CJDG, Silva VJD, Prata A, et al. Cardiac autonomic modulation in hypertensive patients with Chagas' disease. Acta Tropica 2006; 97:188-195.

20. Gurgel CBFM, Almeida EA. Frequency of hypertension in patients with chronic Chagas' disease and its consequences on the heart: a clinical and pathological study. Arq Bras Cardiol 2007; 89:174-182.

21. Bertanha L, Guariento ME, Magna LA, Almeida EA. Clinical and laboratory characterization of hypertensive Chagas' disease patients without evident heart failure. Rev Soc Bras Med Trop 2008; 41:163-168.

22. Cahalin LP, Mathier MA, Semigran MJ, Dec W, Di Salvo TG. The six-minute walk test predicts peak oxygen uptake and survival in patients with advanced heart failure. Chest 1996; 110:325-332. 